\title{
Internal auditor ten behoeve van het maatschappelijk verkeer
}

\author{
R.O.M. de Jaeger
}

\section{Inleiding}

In dit jubileumjaar voor het NIVRA wordt in nogal wat artikelen teruggeblikt. In sommige gevallen is het een terugblik op de voorbije honderd jaar. in andere gevallen wordt vanuit de toekomst teruggekeken op de periode 1995-2020. Aangezien ik geen historicus ben. noch een helderziende, wil ik eigenlijk meer stilstaan bij de huidige situatie in intern accountantsland. Dat hierbij toch ook wel even naar het verleden wordt teruggekeken zal niemand verbazen, want daarin lag de basis voor het huidige beroep. Dat de actuele situatie ook zijn uitwerking zal hebben voor de toekomst, lijkt mij ook vrij logisch. Vandaar dat enig toekomstdenken toch ook niet geheel buiten de scope van dit artikel kan blijven

Vanuit het thema van de jubileumviering 'People for People' wil ik een poging doen om naar het intern accountantsberoep te kijken. Daarbij zal ik in paragraaf 2 eerst nagaan wat de maatschappelijke ontwikkelingen zijn, wat het maatschappelijk verkeer verwacht. Daarna zal ik in paragraaf 3 nagaan wat de gevolgen zijn van deze ontwikkelingen in het maatschappelijk verkeer voor de klanten van de interne accountant, $\mathrm{nl}$. het management in brede zin. In paragraaf 4 wordt vanuit het verwachtingspatroon van de klant vastgesteld wat de gevolgen zijn voor de interne

R.O.M. de Jaeger RA studeerde handelsingenieur (Leuven, België 1977) en postdoctoraal accountancy (Tilburg 1982). Is hoofd interne accountantsdienst AMEV Nederland, voorzitter overlegorgaan Intac, lid programmaraad postdoctorale opleiding operational audit Erasmus Universiteit Rotterdam. accountant. Met andere woorden people (de interne accountants) for people (de klanten van de interne accountants). Paragraaf 5 geeft de conclusie van dit artikel.

\section{Maatschappelijk verkeer}

\subsection{Algemeen}

Interne accountants staan in directe relatie tol het management van het bedrijf waarin ze werkzaam zijn. Dit betekent dat dit in eerste instantie de klanten zijn van de interne accountant. Ik wil echter een stap verder gaan en eerst eens kijken naar het voor accountants zo belangrijke maatschappelijk verkeer. Van oorsprong ontlenen accountants immers in overwegende mate hun functie en bestaan aan dit maatschappelijk verkeer. Bij de externe accountants is dit al jaren duidelijk het geval. Echter ook interne accountants kunnen naar mijn mening een belangrijke rol vervullen in de wensen die de maatschappij heeft ten aanzien van het bedrijfsleven. Deze rol zou zich kunnen beperken tot ondersteuning van het management en commissarissen. Ondanks deze. dan indirecte, relatie is het goed stil te staan bij het maatschappelijk verkeer.

\subsection{Evolutie in de wensen}

Naarmate er een scheiding kwam tussen eigendom en bedrijfsvoering ontstond er behoefte aan onathankelijke controle van de financiële verantwoording. Financiële betrouwbaarheid was de behoefte die zowel eigenaren als bedrijfsleiding hadden; een behoefte waarin werd voorzien door respectievelijk externe en interne accountants (de financial audit). Daarnaast werden geleidelijk 
meer partijen geïnteresseerd in de financiële informatie van het bedrijf zoals crediteuren, werknemers, banken, overheid, e.a. Dit heeft uiteindelijk geleid tot de wettelijke verankering van de externe accountantscontrole.

Door de toenemende mondigheid van het 'maatschappelijk verkeer', het toenemend aantal, vaak grote, faillissementen, fraudes en bedrijven in moeilijkheden, worden nu ook andere eisen gesteld door belanghebbenden bij het bedrijfsleven. Deze eisen zijn niet langer louter van financiële aard.

The Institute of Chartered Accountants of Scotland (1993) heeft over deze (veranderende) wensen van het maatschappelijk verkeer, de indirecte klanten van de interne accountant een zeer lezenswaardig rapport uitgebracht onder de naam Auditing into the Twenty-first Century. Ook in Nederland verwacht het maatschappelijk verkeer meer van de (externe) accountant dan alleen maar een mededeling dat de jaarrekening juist is. in accountantstermen een getrouw beeld geeft. Verwacht wordt ook enige zekerheid over het feit dat de vennootschap niet failliet zal gaan. dat er geen fraude is geweest, dat het bedrijf goed wordt geleid. dat het bedrijf binnen de wet handelt en ook dat het bedrijf verantwoord omgaat met de sociale problematiek in ruime zin.

Dit heeft er mede toe geleid dat diverse soorten audits en audit-beroepsgroepen zijn ontstaan zoals milieu-audit, operational audit, compliance audit, quality audit. management audit, e.a..

\subsection{Wensen geregeld of niet}

In het buitenland heeft aandacht voor de wensen van de klanten bijvoorbeeld geresulteerd in het Treadway-, het COSO- en het Cadbury report. In deze rapporten is echter met name aandacht besteed aan interne controle gericht op financiële verantwoordingen. Daarnaast zijn aanbevelingen opgenomen inzake verantwoordelijkheden van de bedrijfsleiding, commissarissen en accountants. In Nederland zijn er bijvoorbeeld de fraude-richtlijn, het toezicht van De Nederlandse Bank. wet computercriminaliteit e.d..

Mogelijke oorzaken voor deze ruime aandacht die internationaal aan de wensen en verwachtin- gen van het maatschappelijk verkeer wordt gegeven zijn de mate waarin accountants aansprakelijk zijn gesteld voor het (vermeend) falen van de accountantscontrole en het aantal grotere bedrijven dat met financiële problemen heeft te maken gehad. Het mogelijk falen van de accountantscontrole kan direct worden gerelateerd aan de louter financiële benadering, die niet meer in de pas loopt met het verwachtingspatroon.

Ten aanzien van sommige wensen van de klanten moge het duidelijk zijn dat interne controle alleen geen afdoende middel is. Continuïteit, goede bedrijfsleiding en sociaal verantwoord gedrag bijvoorbeeld vragen meer dan interne controle. In het algemeen kunnen we stellen dat interne controle gericht op financiële verantwoordingen door alle ontwikkelingen op een kwalitatief hoger niveau is gebracht. Aan operationele informatie, managementinformatie dus in brede zin. de beheersing van de bedrijfsrisico's en de bedrijfsvoering is nog onvoldoende aandacht besteed. Over deze zaken wil het publiek nog meer zekerheid krijgen. Voor het verschaffen van deze zekerheid kunnen en moeten accountants, en vooral interne accountants, een belangrijke rol spelen.

\section{Management}

\subsection{Gevolgen door maatschappelijke ongeving}

In eerste instantie is bij het management de behoefte gegroeid aan interne controle, namelijk waar het bedrijf steeds groter werd en de greep van de directeur-eigenaar op het bedrijf wat minder werd. Zoals hiervoor reeds vermeld ontstond bij de scheiding van eigendom en leiding ook bij de leiding van het bedrijf zelf behoefte aan zekerheid omtrent de financiële verantwoording (financial audit). Mede door de recente ontwikkelingen in de wensen van het maatschappelijk verkeer, ontstaat er bij het management behoefte zich een oordeel te vormen over het geheel aan beheersingsmaatregelen in het bedrijf. Beheersingsmaatregelen die zijn toegesneden op zowel de eigen interne als de algemeen maatschappelijke problematiek. de managementinformatie.

In eerste instantie is het een belangrijke taak voor de leiding en de toezichthouders (commissa- 
rissen) van de bedrijven om de klanten te geven wat ze vragen. Pas diarna komen de accountants in beeld om ain de beweringen van de bedrijfsleiding een extra zekerheidsdimensie te geven. Er zullen echter problemen blijven om honderd procent zekerheid te geven ten aanzien van een aantal wensen. Immers, het voldoen ain alle wensen is op een aantal gebieden economisch niet verantwoord. Wat zou het niet kosten indien (externe) accountants iedere fraude zouden moeten ontdekken of indien ze in detail zouden moeten nagaan of het bedrijf daadwerkelijk aan alle wetten voldoet. Bovendien kunnen we stellen dat dit zelfs onmogelijk is. Ten aanzien van (mogelijke) fraude kan het publiek wel verwachten dat de bedrijfsleiding en toezichthouders zodanige maatregelen hebben getroffen dat de mogelijkheden van fraude worden beperkt tot een minimum. Indien fraude toch voorkomt dient het management dusdanige maatregelen te hebben getroffen dat de kans op ontdekken zo groot mogelijk is, ook al is de fraude niet materieel voor de jaarrekening.

De verwachtingen ten aanzien van faillissement hangen samen met de impliciete veronderstelling van continuitteit bij het opstellen van jalarrekeningen. In sommige omstandigheden hadden directie, commissarissen en/of accountants hier misschien meer alandacht aan moeten besteden. Mogelijk dat het uitdrukkelijk vermelden van dit continuiteitsprincipe in de jaarrekening to extra voorzichtigheid en zekerheid kan leiden.

Het punt van de goede bedrijfsleiding is met name een aandachtspunt voor de commissarissen; zij zijn er in eerste instantie verantwoordelijk voor dat het bedrijf goed wordt geleid.

Ten aanzien van de naleving van de overige wettelijke en sociale verplichtingen is de bedrijfsleiding verantwoordelijk voor het treffen van voldoende maatregelen om een goede naleving te kunnen vaststellen. Commissarissen zullen hier vervolgens toezicht op uitoefenen. Ten alanzien van sociale verplichtingen en verantwoordelijkheden ligt een en ander een stuk moeilijker indien dit niet in wetten is verwoord. Hier zouden commissarissen van het bedrijf wel een gedragscode kunnen eisen, waarin is opgenomen hoe (het personeel van het bedrijf zich in ruime zin dient te gedragen.

\subsection{Gewijaigde wensen management}

De bedrijtswoering zelf is steeds complexer geworden door toenemende concurrentie en de snelheid waarmee veranderingen zich voordoen. Door fusies en/of zelfstandige groei ontstaan steeds grotere conglomeraten, waardoor het voor het (top)management steeds moeilijker wordt om een goed totaalbeeld te krijgen van het bedrijf en zijn samenstellende delen. Daarnaast worden steeds meer bedrijven gereorganiseerd in business units of divisies met daaraan gekoppeld een verdergaande delegatie van bevoegdheden. Zie ook het artikel van Driessen en Molenkamp in Managerial Auditing Journal van 1993.

Naast maatschappelijke eisen krijgt het management mede hierdoor behoefte aan een verdergalande ondersteuning in de beheersing van het bedrijfsgebeuren. Dit alles heeft ervoor gezorgd dat er belangrijke verschuivingen zijn gekomen van interne controle nalar internal audit die meer dient te omvatten dan alleen een oordeel over de getrouwheid van een jaarrekening. Het management heeft ook behoefte aan een onafhankelijk onderzoek en oordeel over de beheersing van de bedrijfsprocessen en bedrijfsonderdelen (operational audit) inclusief adviezen ter verbetering van deze processen en onderdelen.

\section{Betekenis voor interne accountants}

\subsection{Algemeen}

Vanuit de behoefte van interne accountants om hun toegevoegde waarde aan te tonen en vanuit de gewijzigde behoeften van de directe klanten. het management. en de indirecte klanten. het maatschappelijk verkeer, zijn verscheidene groeperingen bezig met de ontwikkeling van het interne accountantsberoep. Om verwarring te voorkomen met het "oude" beeld van de interne accountant. namelijk de financial auditor, wordt meer en meer internal auditor gebruikt om alan te geven dat het taakgebied van de interne accountant is verruimd. Het taakgebied verschuift van overwegend certificerend natar risicobeheersend, ondersteunend en adviserend.

Het Intac (de groepering van interne accountants deel uitmakend van het NIVRA) staat op het 
punt, na een uitgebreide discussie met de achterban, een profielschets voor internal audit in Nederland af te ronden. De recent opgerichte Vereniging voor Register Operational Auditors is ook haar weg aan het zoeken op een terrein dat in belangrijke mate overeenkomt met dat van de internal auditors. Op Europees niveau is de European Confederation of Institutes of Internal Auditing een position paper aan het voorbereiden over Internal Auditing in Europe. Al deze acties lijken heel intern gericht en hebben wel eens de neiging om te verzanden in academische discussies en theoretische modellen. Waar het echter allemaal om gaat zijn de veranderende wensen van de klanten, van het management en het maatschappelijk verkeer. Bij al de voornoemde activiteiten van het interne accountantsberoep worden deze wensen uitdrukkelijk als uitgangspunt genomen.

Voor de interne accountants hebben de hiervoor genoemde verschuivingen in het wensenpakket van het maatschappelijk verkeer en van het management directe gevolgen. Hierbij kan gedacht worden aan de taak van de interne accountant, regulering van het beroep. de positionering van het beroep. de kwaliteit, de opleiding en de verhouding met de externe accountant. Op sommige van deze gebieden hebben zich al ontwikkelingen voorgedaan, op andere gebieden zullen de ontwikkelingen nog verder gestalte (moeten) krijgen.

\subsection{Taakverschuiving}

De taakverschuiving van financial naar internal audit heeft beslist ook economische achtergronden. Daarnaast durf ik te stellen dat ook de veranderde wensen van de klanten een invloed hebben c.q. zullen hebben op het taakgebied van de interne accountant. Financial audit is immers op het verleden gericht en op een toestand op een bepaald moment.

Het maatschappelijk verkeer en het management willen een meer toekomstgericht oordeel hebben en een oordeel dat de hele bedrijfsvoering omvat. Hierbij denk ik vooral aan het faillissementsvraagstuk en de competentie van de bedrijfsleiding. Op geen van deze punten zal een internal auditor absolute zekerheid kunnen geven, maar hij kan wel een oordeel geven over de manier waarop de bedrijfsleiding het bedrijf beheerst. De internal auditor beweegt zich daarom meer en meer op het terrein van de beheersingsmaatregelen en het meetinstrumentarium van het bedrijf en doet daarover uitspraken. Goede beheersingsmaatregelen en een goed meetinstrumentarium geven meer zekerheid ten aanzien van de toekomst van de onderneming en de kwaliteit van het management. Zekerheid ligt uiteindelijk wel in het financiële, maar daaronder liggen allerhande niet direct financiële aspecten die wel degelijk ook van belang zijn voor de continuiiteit. Deze aspecten vertaald in diverse kwantitatieve en kwalitatieve doelstellingen dienen integraal deel uit te maken van het beheersingsinstrumentarium van het bedrijf en zullen een belangrijk aandachtspunt zijn voor de internal auditor.

De wensen op de andere punten en in de financiële hoek zorgen er voor dat er derhalve ook meer aandacht wordt gevraagd van de interne accountant voor interne controles. Deze hebben dan zowel betrekking op het financiële verslagleggingstraject als op gebieden die meer aansluiten op de wensen van het publiek ten aanzien van fraudes en de naleving van wettelijke en sociale verplichtingen.

\subsection{Regulering van het beroep}

In Nederland is de regelgeving voor het beroep van internal auditor nog vrij beperkt en bovendien afkomstig uit het accountantsberoep zelf. In sommige landen begint er stilaan wel enige externe regulering te ontstaan. Dit gebeurt dan vooral in de financiële sector en bij de overheid.

Om, voor zover mogelijk, tegemoet te komen aan de wensen van de klanten is diepgaande kennis van het bedrijf noodzakelijk. Aan de wensen van de klanten dient op een zo economisch mogelijke manier te worden tegemoet gekomen. Om beide redenen zijn internal auditors meer aangewezen dan de externe accountants om de gewenste extra zekerheden te verschaffen. Dit kan echter ook meteen inhouden dat, net als voor het externe accountantsberoep, ook internal auditors met verdergaande regelgeving zullen moeten leren leven omdat ook zij een rol zullen vervullen richting het maatschappelijk verkeer. Indien dit daadwerkelijk het geval wordt, ben ik van mening dat Europese regelgeving het meest voor de hand ligt. Indien regelgeving niet op Europees niveau zou gebeuren, krijgt het bedrijfsleven te maken met verschillende wettelijke vereisten die mogelijk 
concurrentievervalsend zouden kunnen werken. Overigens wil ik hier wel opmerken dat de internal auditors, zeker zij die zijn angesloten bij het IIA. al in belangrijke mate voor zelfregulering hebben gezorgd.

\subsection{Positionering van het beroep en de dienst}

Binnen de maatschappij zal interne accountancy of beter internal audit een eigen specifieke plaats moeten krijgen. Hiervoor zullen zowel nationale als internationale beroepsorganisaties de nodige stappen moeten nemen richting overheid, bedrijfsleven en maatschappelijk verkeer. Hierbij dient aandacht te worden besteed aan de kennis en kunde van de internal auditors en vooral ook alan de onpartijdige positie die ze innemen ten opzichte van het management. Deze onpartijdige positie dient nog meer versterkt te worden tot een onafhankelijke positie binnen de onderneming door internal auditors ook te laten rapporteren aan een audit committee waarin leden of vertegenwoordigers van de raad van commissarissen zitting hebben.

Binnen het bedrijf zal de internal auditor zich verder moeten profïleren als de vooruit-en meedenkende accountant. als de accountant die hét instrument van het management is voor diens oordeelsvorming over de mate waarin risico"s worden beheerst.

\subsection{Kwaliteit en opleiding}

Deze beide elementen wil ik samen nemen omdat opleiding en permanente voortgezette educatie een duidelijke basis vormen voor de $k$ waliteit van de interne accountants. In de opleiding voor interne accountant zal veel meer aandacht moeten worden besteed alan managementaspecten en beheersing van bedrijfsrisico's. Ik ben het met L. Paape (1995) eens dat de huidige registeraccountantsopleiding onvoldoende is toegesneden op de internal audit functie en nog te eenzijdig gericht is op de certificerende functie. Daar waar de opleiding al meer op de interne accountant is gericht speelt het probleem dat het beroep nog volop in ontwikkeling is en dat een stabiele opleiding vrij moeilijk te realiseren is in een instabiele interne accountantsomgeving.

\subsection{Verhouding met de externe accountant}

Gezien de wensen van het maatschappelijk verkeer en de manier waarop ik meen dat daaraan invulling kan worden gegeven, denk ik met het Institute of Chartered Accountants of Scotland (1993) dat de rol van de externe accountants (nog) meer die zal worden van kwaliteitscontroleurs van de internal auditors. De externe accountant zal een 'kwaliteitskeurmerk' geven aan het werk van de internal auditor ten behoeve van het management, de commissarissen en indirect het maatschappelijk verkeer. Hierdoor wordt zekerheid gegeven dat de internal auditor op een goede manier heeft toegezien op de risico-beheersing binnen het bedrijf en dat hij daar de adequate conclusies uit heeft getrokken. Op deze manier wordt indirect. maar wel op een ruimer gebied. ook meer zekerheid gegeven aan het maatschappelijk verkeer. Indien externe accountants ook de internal audit functie zouden willen vervullen, ontbreekt het hun veelal aan de noodzakelijke diepgaande bedrijfskennis. Daarnaast ontbreekt het hun ook aan de permanente aanwezigheid wat met name ook richting management een belangrijk punt is. Bovendien lijkt de vraag gerechtvaardigd of deze vorm van auditing zich verhoudt tot diens certificerende functie. In dit kader wil ik vast ook wijzen op een ontwikkeling in de USA waar R.T. van Brunt. Assistant Chief Accountant bij de SEC, heeft gesteld dat: 'The SEC will question independence... when external auditors perform procedures that are management or internal control functions.'

\section{Conclusie}

De behoeften van het maatschappelijk verkeer en van het management zijn veel breder geworden. waardoor ook andere eisen worden gesteld aan de interne accountants. De enge behoefte aan zekerheid omtrent de betrouwbararheid van de financiële informatie heeft plaats gemaakt voor een ruimere behoefte aan zekerheid omtrent de bedrijfsvoering in zijn totaliteit. Deze ruimere behoefte aan zekerheid kan het best door de interne accountant worden ingevuld. Hierdoor is de taak van de interne accountant aan het verschuiven van financial audit naar internal audit. Doordat hij deze ruimere zekerheid verschaft aan het management en de commissarissen, heeft hij op die manier ook een (indirecte) verantwoordelijkheid 
richting het maatschappelijk verkeer. Dit houdt tevens in dat er nog meer aandacht zal moeten worden besteed aan onafhankelijkheid, kwaliteit en deskundigheid. zaken die uitdrukkelijk naar voren komen in de profielschets die Intac aan het afronden is.

In de voorbije honderd jaar heeft het interne accountantsberoep te maken gehad met de nodige veranderingen, zowel in de omgeving waarin ze hebben gewerkt als in de uitoefening van hun taak. Aan de recente ontwikkelingen is ook al aandacht besteed in een artikel van P.P.M. Ekelschot (1993). Deze veranderingen zullen in de toekomst zeker niet minder worden omdat naar mijn mening ook aan interne accountants een ruimere maatschappelijke verantwoordelijkheid zal worden gegeven. Indien we als beroepsgroep echter heel uitdrukkelijk onze blik op de klant richten, blijven we uitzicht houden op c.q. krijgen we een mooie toekomst voor het beroep. Dit geldt zowel in de Nederlandse als in de internationale verhoudingen.

\section{I T E R A T U U R}

The Institute of Chartered Accountants of Scotland, (1993), Auditing into the twenty-first century, Edinburgh.

Driessen, A.J.G. en Molenkamp, A., (1993), The Perspective of Operational Auditing : A New Management Tool, Managerial Auditing Journal, Vol. 8 No. 5 p. 19-25.

Ekelschot, P.P.M., (1993), Ontwikkelingen in het beroep van intern accountant, De Accountant nr. 7, maart, p. 425428.

Paape, L., (1995), Internal control en de drijvende continente van external en internal auditing, De Accountant nr. 6, februari, p. 396-401. 